\title{
Neonatal sepsis and its association with birth weight and gestational age among admitted neonates in Ethiopia: systematic review and meta-analysis
}

\author{
Amare Belachew* and Tilahun Tewabe
}

\begin{abstract}
Background: Neonatal sepsis is an invasive infection, usually bacterial, and often occurring during the neonatal period (0-28 days). Neonatal sepsis causes a high burden of morbidity and mortality in developing countries like Ethiopia. There are fragmented, inconsistency, and no review has been conducted to report the magnitude and associated factors of neonatal sepsis in Ethiopia. Thus, this study aimed to assess the pooled prevalence of neonatal sepsis and its association with birth weight and gestational age among admitted neonates in Ethiopia.

Methods: Electronic media searches like PubMed, CINHAL, EMBASE, Google Scholar, Web of Science, Cochrane library databases and African health science library were used. All original peer-reviewed papers which reported the prevalence of neonatal sepsis in Ethiopia were included in this study. Two reviewers independently extracted the data using a standardized data extraction format for eligibility and appraised their quality. Data were analyzed using Stata version 14 software. The pooled prevalence of neonatal sepsis was estimated with the random-effect model. Heterogeneity between studies was assessed by $I^{2}$ statistics test. Subgroup and meta-regression analyses were done to assess the source of variation between the studies. Egger's test followed by trim and fill analysis were used to determine publication bias. A sensitivity analysis was carried out.

Result: A total of 952 research papers reviewed, of which, eight studies were finally included in this systematic review and meta-analysis. The random effect pooled prevalence of neonatal sepsis in Ethiopia was 49.98\% (Cl: 36.06, 63.90). In subgroup analysis, the pooled estimated neonatal sepsis among cross-sectional studies was 53.15\% while the cohort was 40.56\%. Newborns with a birth weight of less than $2.5 \mathrm{~kg}$ were 1.42 times more likely to develop neonatal sepsis infection compared to normal babies. The odds ratios of preterm babies were 3.36 to develop neonatal sepsis compared to term infants.
\end{abstract}

Conclusion: The pooled prevalence of neonatal sepsis in Ethiopia was high. Thus, health care providers should adhere to aseptic precautions while performing procedures, especially in preterm and low birth weight infants were recommended.

Keywords: Neonatal sepsis, Prevalence, Determinants, Newborn, Ethiopia

\section{Background}

Neonatal sepsis is a bloodstream infection. It is a major cause of morbidity and mortality for newborns. It can be categorized as early onset or late onset neonatal sepsis. Of newborns with early onset sepsis, $85 \%$ present within $24 \mathrm{~h}, 5 \%$ present at $24-48 \mathrm{~h}$, and a smaller percentage present within $48-72 \mathrm{~h}$ [1]. Early onset neonatal sepsis is associated with the acquisition of microorganisms from the mother, birth canal during delivery [1].

\footnotetext{
* Correspondence: belamare8@gmail.com; dagnewamare@gmail.com

College of Medicine and Health Science, Bahir Dar University, Bahir Dar Ethiopia

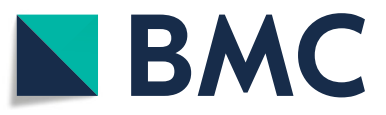

(c) The Author(s). 2020 Open Access This article is distributed under the terms of the Creative Commons Attribution 4.0 International License (http://creativecommons.org/licenses/by/4.0/), which permits unrestricted use, distribution, and reproduction in any medium, provided you give appropriate credit to the original author(s) and the source, provide a link to the Creative Commons license, and indicate if changes were made. The Creative Commons Public Domain Dedication waiver (http://creativecommons.org/publicdomain/zero/1.0/) applies to the data made available in this article, unless otherwise stated. and effective care after birth [4]. 1999 and it decreased to 2.5 million in 2017 [2]. More than $40 \%$ of all deaths in children younger than five years of age occurred during the neonatal period [3]. The 2016 Ethiopian Demographic Health Survey (EDHS) reported one in every 35 children died within the first months of life [2].

Newborns are the most vulnerable children and many conditions that result in a newborn death can easily be prevented by providing a combined approach to the mother and her baby during her pregnancy, delivery, 
Infection, cord strangulation, and asphyxia are the common causes of neonatal deaths [5]. Although different studies were conducted to assess the magnitude and associated factors of neonatal sepsis in Ethiopia [4-13], the findings were inconsistent and varied. As documented in different kinds of literature, most frequently factors caused neonatal sepsis were low birth weight, preterm birth, maternal infection, prolonged labor, prolonged rupture of membrane, a complication of pregnancy and instrumental delivery [6-12]. Other like asphyxia [4], size of the neonate at birth and neonatal care practice, number of pregnancy, maternal morbidity were less frequently cause neonatal sepsis [9].

There are fragmented studies that were done to estimate the magnitude of neonatal sepsis and associated factors in Ethiopia. However, the prevalence of neonatal sepsis ranges from $78.6 \%$, in Shashemene, Oromia region [6] to $23.8 \%$ in Bahir Dar [12]. It showed that there is a high discrepancy of study findings and there was no nationwide study that represents the pooled prevalence of neonatal sepsis in Ethiopia. Thus, the purpose of this study was to estimate the pooled prevalence of neonatal sepsis and its association with birth weight and gestational age in Ethiopia.

\section{Methods}

\section{Search approach and appraisal of studies}

The Preferred Reporting Items for Systemic Reviews and Meta-analysis (PRISMA) guideline was followed for this systematic review and meta-analysis [14]. Studies that addressed neonatal sepsis and its association with birth weight and gestational age in Ethiopia were included. EMBASE, PubMed, Google Scholar, CINHAL and Cochrane library were searched. The strategy of searching was carried out using the following searching terms like: "prevalence", "neonatal sepsis", "NICU", hospital, < 28 days of birth, and "Ethiopia". The search terms were used in combination and separately using Boolean operators "AND" or OR "” or AND,NOT or AND, NOT. Endnote reference manager software was utilized.

\section{Inclusion and exclusion criteria}

Studies were eligible for inclusion if they: (1) were done in regards neonatal sepsis and its associations with birth weight and gestational age in Ethiopia, with the design of cross-sectional and a cohort studies; (2) reported with the English language; (3) No restrictions were placed on study settings. Studies were excluded if they are single case study design or qualitative study and were published in a book, or report.

\section{Measuring outcome variables}

The outcome of this review was prevalence of neonatal sepsis among admitted newborns. Neonatal sepsis is defined as neonates with presence of at least one clinical sign plus at least two laboratory results which are suggestive for neonatal sepsis (WBC, ESR, Platelet count, CRP, ANC, and Blood glucose) or neonates who are diagnosed as sepsis by attending physician and fulfill sepsis criteria within 0-28 days of life. The second outcome of the study was to determine the association between neonatal sepsis with birth weight and gestational age.

\section{Study screening and selection}

Two independent reviewers extracted the data by using the standard format which includes year of publication, primary author, study design, study setting, sample size, a region of the study, response rate and prevalence of neonatal sepsis. They independently carried out data extractions and article inclusions. Disagreements of article inclusion were resolved with discussion and consensus. Studies that met the NewcastleOttawa Scale tool, criteria in terms of enough sample size, clarity of research aims, appropriateness of design, recruitment, data collection, analysis and reporting results were included in the review. Then the full-text of potentially eligible papers assessed against the inclusion criteria. The relevance of the reviewed studies checked based on their topic, objectives, and methodology. Newcastle-Ottawa Scale was used to give a score for articles (NOS) $[15,16]$. Finally, articles with a score of $\geq 6$ were included in the final analysis.

\section{Statistical analysis}

Microsoft Excel spreadsheet and Stata version 14 software were used to extract and analyzed the data, respectively. $\mathrm{I}^{2}$ statistics test was used to quantify heterogeneity among studies [17]. Laird's random Effects model was used to estimate the pooled prevalence of neonatal sepsis. Subgroup analysis was done by study setting to minimize the random variations between the point estimates of the primary studies. Furthermore, univariate meta-regression analysis was undertaken by sample size, study design, region, and publication date. The association between neonatal sepsis infection with birth weight and gestational age were determined with odds ratio.

\section{Publication bias}

Begg and Egger's test of the intercept and the funnel plot of precision asymmetry used to detect publication bias [18].

\section{Results}

About 952 articles regarding neonatal sepsis were retrieved in Google scholar, PubMed, EMBASE, CINHAL, and Cochrane and using other databases. Among them, 939 were excluded due to duplications and irrelevancies, 13 articles were enrolled for abstract and title screen. Thirteen studies fulfilled the eligibility criteria and from them, five studies were excluded since they did not report the outcome variable [11, 19-22]. Finally, 8 studies were included in this systematic review and metaanalysis (Fig. 1). 


\section{Characteristics of original studies}

As described below Table 1, these 8 studies were published from 2014 to 2018. In the current systematic review and meta-analysis, 9032 live births were involved to estimate the pooled prevalence of neonatal sepsis among newborns. Both cross-sectional and cohort study designs were included in this study. The highest prevalence $(77.8 \%)$ of neonatal sepsis was reported in Gonder Town, Ethiopia [6] while the lowest prevalence $(23.8 \%)$ was reported in Bahir Dar, Amhara region [12]. In this meta-analysis, three regions of the country were represented; two studies were from the Amhara region [6, 12], one study was from Tigray [23] and five studies from the Oromia region $[7-10,13]$. Six studies were conducted using a cross-sectional study design while two were cohort studies (Table 1).

\section{Publication bias}

Begg and Egger's test showed that there is no publication bias with a $p$-value of $(p=1)$ and $(p=0.615)$, respectively. The Egger's test of the intercepts (B0) was 0.089(CI -0.322, 0.50).

\section{Meta-analysis}

In this study, the pooled prevalence of neonatal sepsis was $49.98 \%$ with a confidence interval of (CI: 36.06, 63.99). A random-effect model was employed to estimate the pooled prevalence of neonatal sepsis due to severe heterogeneity $\left(\mathrm{I}^{2} 96.4, p\right.$-value $\left.=0.000\right)$ was observed between the studies. Furthermore, subgroup analysis was done by region, sample size, publication year and study design but none of them were significant (Fig. 2).
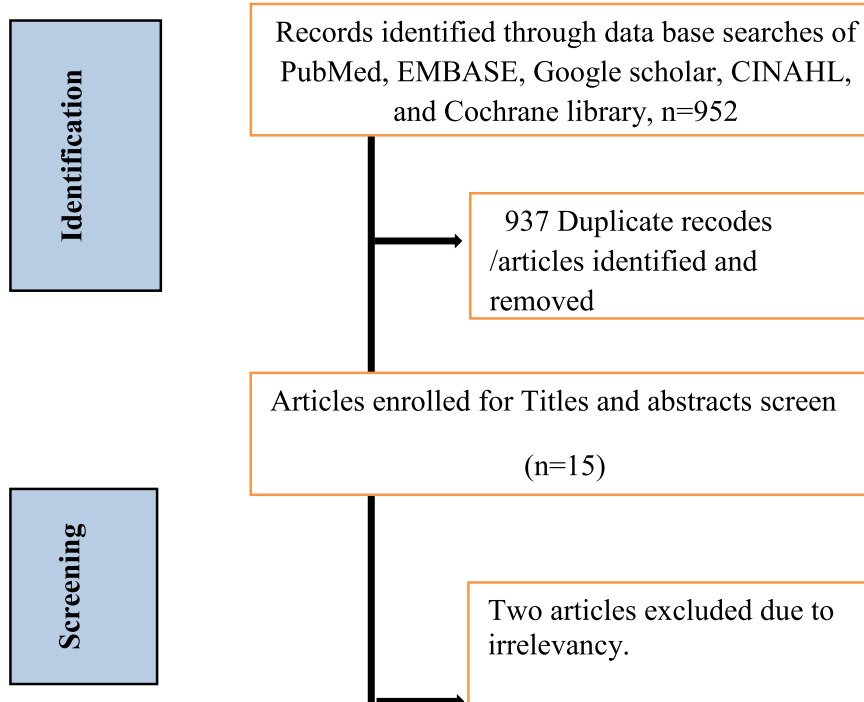

Articles enrolled for Titles and abstracts screen

$(\mathrm{n}=15)$
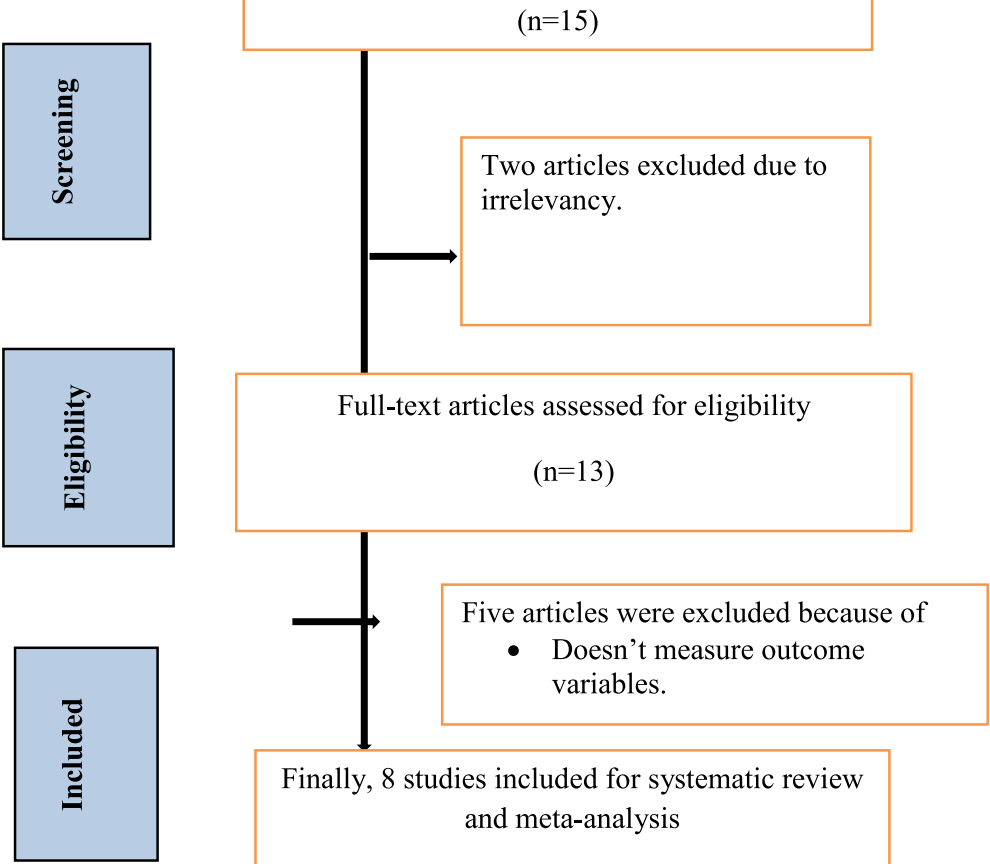

Finally, 8 studies included for systematic review and meta-analysis

Fig. 1 Flowchart diagram to reflect the selection of studies for systematic review and meta-analysis of the prevalence of neonatal sepsis and its association with birth weight and gestational age in Ethiopia 
Table 1 Descriptive summary of 8 studies included in the meta-analysis of the prevalence of neonatal sepsis in Ethiopia, 2018

\begin{tabular}{llllllll}
\hline Authors /Year of publication & Region & Study setting & Study design & Response rate & Sample size & Out-come & Prevalence \\
\hline Demessie AG et al. 2017 [6] & Amhara & Institutional based & cross sectional & $100 \%$ & 769 & 522 & 67.9 \\
Getablew A et al. 2018 [7] & Oromiya & Institutional based & cross sectional & $100 \%$ & 244 & 190 & 77.86 \\
Tewabe T et al. 2018 [12] & Amhara & Institutional based & cross sectional & $100 \%$ & 391 & 93 & 23.8 \\
Woldu MA et al. 2017 [8] & Oromiya & Institutional based & cross sectional & $100 \%$ & 306 & 229 & 74.83 \\
Roba et al. 2017 [10] & Oromiya & Institutional based & cross sectional & $100 \%$ & 3418 & 1207 & 35.31 \\
Sime H et al. 2014 [13] & Oromiya & Institutional based & Cross sectional & & 225 & 40 & 40 \\
Gerenesea H et al. 2017 [23] & Tigray & Institutional based & Cross sectional & $100 \%$ & 246 & 49 & 22.7 \\
Debelew GT et al 2014 [9] & Oromiya & Institutional based & cohort & $100 \%$ & 3463 & 1188 & 34.3 \\
\hline
\end{tabular}

\section{Meta regressions}

Univariate meta-regression analysis was used to investigate the source of variation between studies by study design, publication date, sample size, region, and study design but none of them were statistically significant (Table 2). Furthermore, a sensitivity analysis was carried out and all studies were under the confidence intervals.

\section{Association between birth weight and neonatal sepsis} Four studies $[6-8,22]$ were used to examine the association between neonatal sepsis with birth weight (Fig. 3). The analysis revealed that neonatal sepsis was significantly associated with the low birth weight with OR 1.42 (95\% CI, 1.07, 1.88). This metaanalysis showed that the odds ratio of low birth weight was 1.42 times to develop neonatal sepsis than normal-weight born babies. The Begg and Egger tests showed that there was no publication bias with the $p$-value of $(P=0.497)$ and $(p=0.076)$, respectively. The Egger test with the $\mathrm{Bo}=2.797(-0.722,6.32)$.

\section{Association between gestational age and neonatal sepsis}

The third outcome of this study was to determine the association between gestational age and neonatal sepsis. The analysis of these four studies [6-8, 22] revealed that neonatal sepsis was significantly associated with the gestational age of newborn with OR 3.36 (95\% CI: 2.50, 4.54). Preterm babies were 3.36 more likely to develop neonatal sepsis than term babies. The Begg and Egger tests showed that there was no publication bias with $P$ value $(P=0.497)$ and $(\mathrm{p}=0.076)$, respectively. The Egger test with the $\mathrm{Bo}=2.797(-0.722,6.32)$ (Fig. 4).

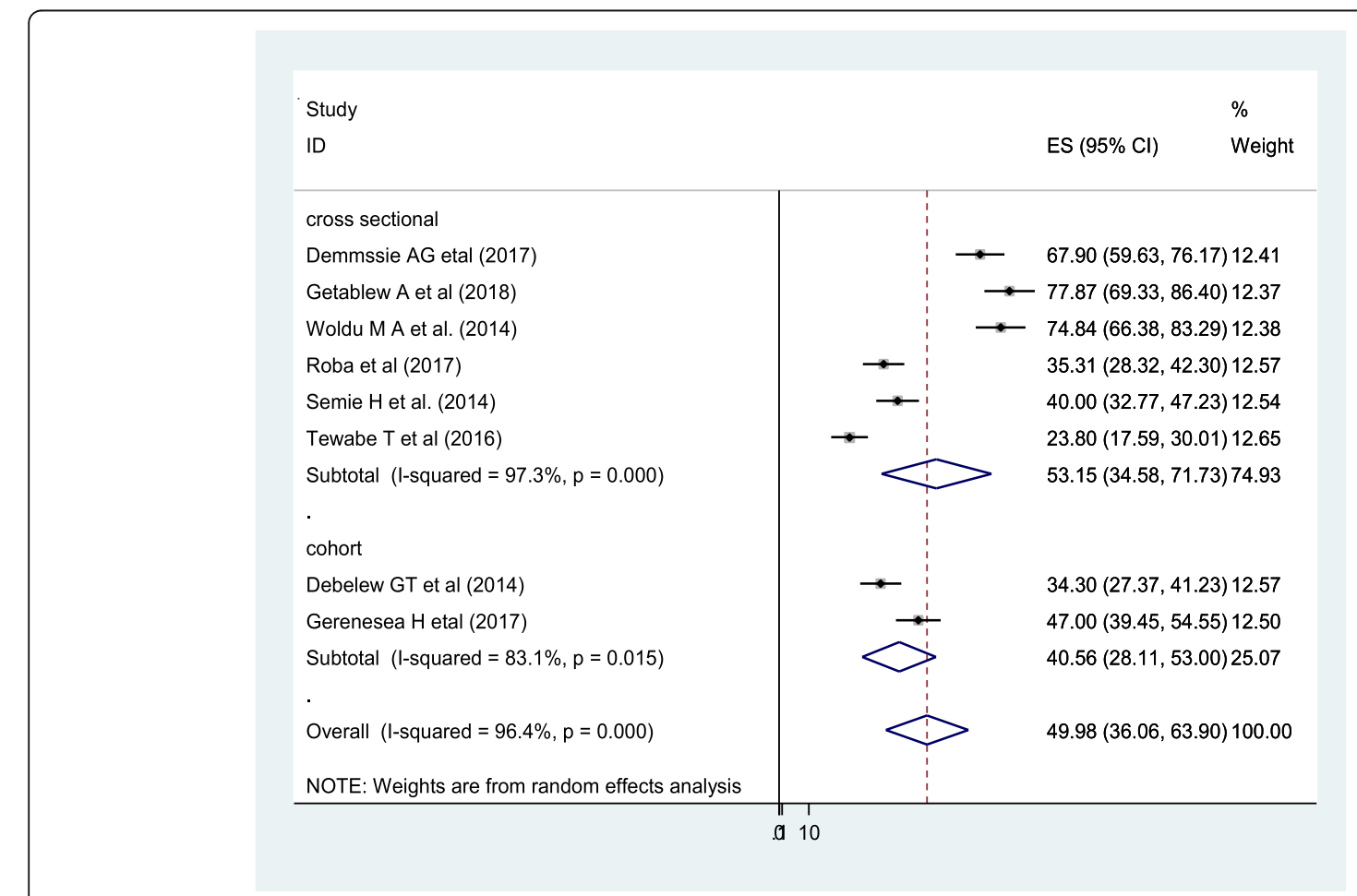

Fig. 2 Subgroup analysis and prevalence of neonatal sepsis in Ethiopia, 2018( $n=8)$ 
Table 2 Univariate Meta-regression analysis of studies on neonatal sepsis infections in Ethiopia, 2018

\begin{tabular}{llll}
\hline & & Co-efficient & $P$ value \\
\hline Publication year & & 1.3 & 0.911 \\
Sample size & & 0.01 & 0.9 \\
Region & Amhara & -23.8 & 0.6 \\
& Oromiya & -12.7 & 0.74 \\
& Tigray & 1 & \\
Study design & Cross sectional & 1 & \\
& Cohort & -22.7 & 0.46
\end{tabular}

\section{Discussion}

This systematic review and meta-analysis showed the pooled prevalence of neonatal sepsis and its association with birth weight and gestational age among admitted neonates. The pooled prevalence of neonatal sepsis among newborns in the first 28 days of life was $49.98 \%$ (CI: 36.06, 63.90). The findings of this review was similar to the global report of the burden of pediatric and neonatal sepsis, $48 \%$ [24], but it is higher than studies done in; Kenya, 23.9\% [25], Nigeria, 18.2/1000 live births [26], India, 7.6\% [27], Temeke and Mwananyamala hospitals, Tanzania, 31.4\% [28], and Egypt, 45.9\% [29]. This may be due to difference in socio-demographic characteristics of respondents, diagnostic modalities, low antenatal care visits in the country, which is $62 \%$ and only $26 \%$ of mothers gave birth in health facilities and the high prevalence of low birth weight and preterm births [4] compared to other countries. Because of this, the prevalence of neonatal sepsis is high in this study compared to other studies. Even though the Ethiopian government implements different strategies to reduce early neonatal infections, still the burden is prevalent and further work is needed to reduce deaths related to newborn sepsis. Therefore, improving antenatal service usage and encouraging mothers to give birth at health institutions will help to reduce early neonatal sepsis especially for low birth and preterm deliveries.

The current studies finding also high compared to systematic review and meta-analysis done in developed countries, 17.2\% [30]. This huge difference may be due to lack of health facilities, early diagnostic or screen modalities and prompt treatment actions between this study and developed countries.

Based on subgroup analysis, the higher pooled prevalence of neonatal sepsis was found from cross-sectional studies (53.15\%) compared to cohort studies (40.56\%). The possible explanation is since the cross-sectional study is one spot study and the prevalence may be high due to seasonal variations.

Neonatal sepsis was influenced by different factors. Preterm newborn babies were 3.36 times more likely to develop neonatal sepsis compared to term newborns. This finding is in line with studies done in Tanzania [28], USA [29, 31] and China [32]. The possible explanation is that preterm babies have immature immune

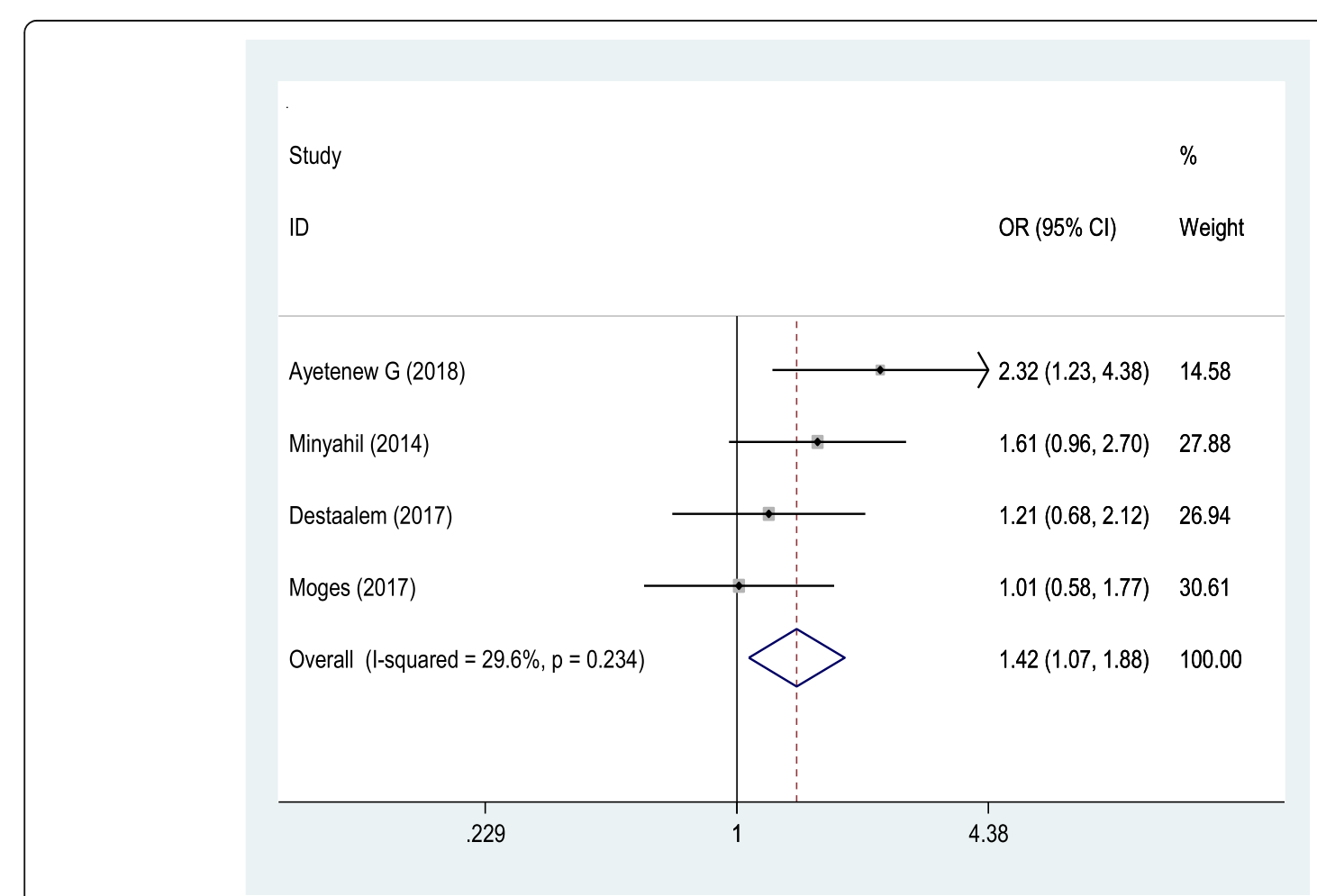

Fig. 3 The pooled odds ratio of the association between birth weight and the occurrence of neonatal sepsis in Ethiopia 


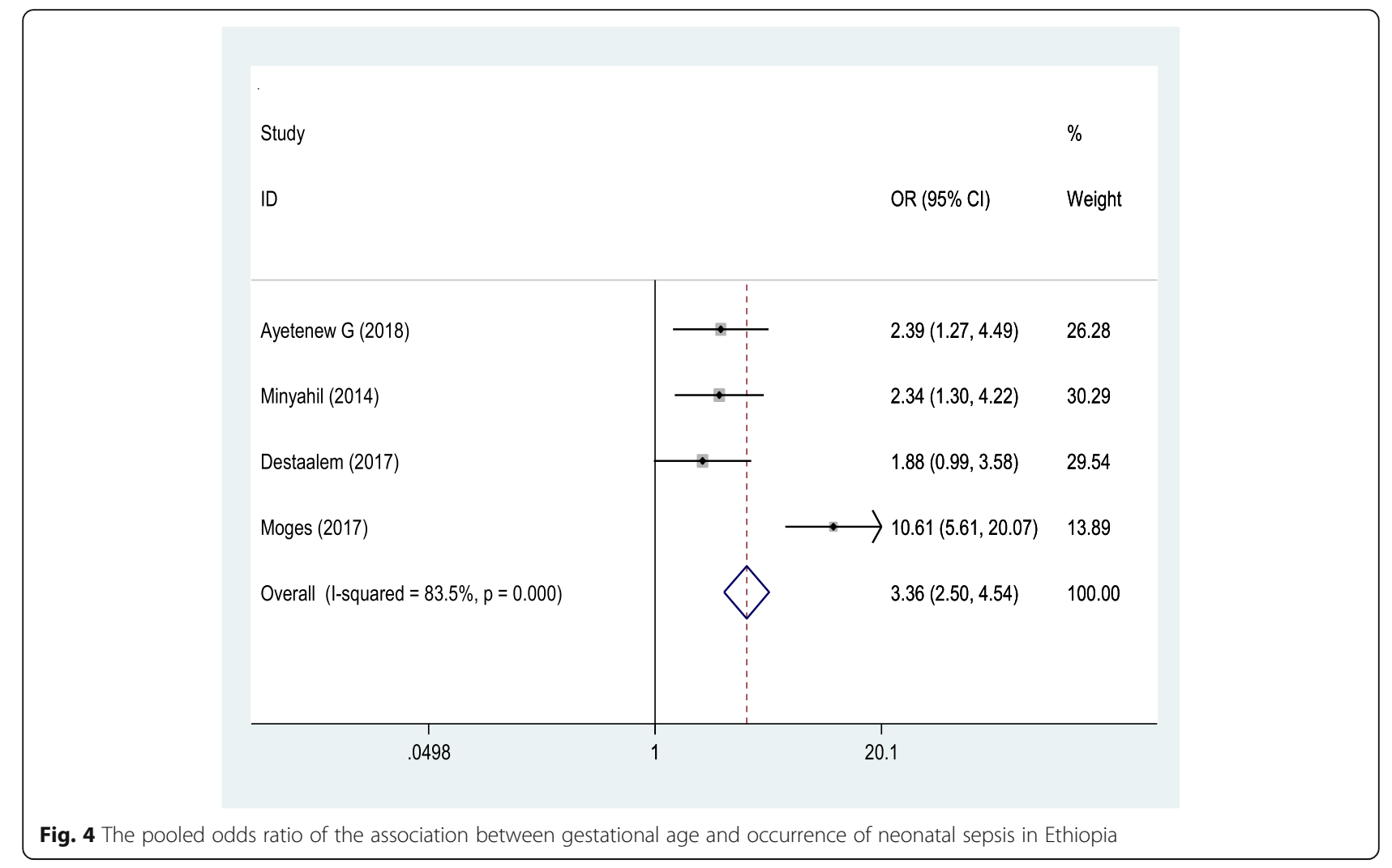

systems (low neutrophil storages) and body organs that fight infections. Due to this, when health professional undergoing procedures like invasive treatment and may be exposed to nosocomial infection, they are more likely prone to develop neonatal infections. There is rapid exhaustion of bone marrow reserve during sepsis. Nowadays immune replacement therapies are widely explored for correcting the immune deficiencies of preterm, and it prevents neonatal infections. Therefore, staff training and education about infection prevention is a crucial step to prevent nosocomial infections.

The birth weight of the newborn was one of the determining factors for neonatal sepsis. Newborns with less than $2.5 \mathrm{~kg}$ were 1.42 times more likely to develop neonatal sepsis than newborns born with $2.5 \mathrm{~kg}$ and above. This finding is consistent with studies done in Afghanistan [33], Sweden [34] and Spain [35]. This may be due to low birth weight newborns are mostly premature, have immature immune system, unable to feed, easily lose their heat, low store of glucose and more likely risk to develop hypoglycemia may increases the likelihood of neonatal infections.

\section{Limitation}

Since it is a first systematic review, lack of enough literature, and use odds ratio to estimate the predictor variables may be affected by other confounding variables. Limited available of studies and low sample size might affect the pooled prevalence.

\section{Conclusion}

The pooled prevalence of neonatal sepsis in Ethiopia was high. Therefore, it is recommended to have more skilled health personnel and advanced equipment while providing maternal and neonatal health care services. Health care providers should adhere to aseptic precautions while performing procedures, especially on low birth weight and preterm infants.

\section{Acknowledgments \\ Not applicable.}

\section{Authors' contributions}

$A B$ : conception of the research protocol, study design, literature review, data extraction, data analysis, interpretation and drafting the manuscript. T: Data analysis and reviewing the manuscript. $A B, T$ : Data extraction and quality assessment. Both authors have read and approved the manuscript.

\section{Funding}

Not applicable.

Availability of data and materials

Identifying/confidential patient data should not be shared.

Ethics approval and consent to participate

Not applicable.

Consent for publication

Not applicable.

Competing interests

The authors declare that they have no competing interests. 
Received: 2 July 2019 Accepted: 29 January 2020

Published online: 05 February 2020

\section{References}

1. Ann L Anderson-Berry, Linda L Bellig, Bryan L Ohning. Neonatal Sepsis. 2015. Available at: https://medlineplus.gov/ency/article/007303.htm.

2. Central Statistical Agency (CSA) [Ethiopia] and ICF. 2017. 2016 Ethiopia Demographic and Health Survey Key Findings. Addis Ababa: CSA and ICF; 2017.

3. WHO. Neonatal mortality. Global Health Observatory. WorldHealth Organization.2018. Available at: http://www.who.int/gho/child_health/ mortality/neonatal/en/

4. Gro Harlem Brundtland, "Plenary Address" (delivered at United Nations General Assembly Special Session on Children. New York: WHO; 2002. https://www.who.int/dg/brundtland/speeches/2002/en/.

5. Afolabi BM. Sub-Sahara African Neonates-Ghosts to Statistics. J Neonatal Biol. 2017;6(1):2167-0897.

6. Demisse AG, Alemu F, Gizaw MA, Tigabu Z. Patterns of admission and factors associated with neonatal mortality among neonates admitted to the neonatal intensive care unit of University of Gondar Hospital, Northwest Ethiopia. Pediatric Health Med Ther. 2017:8:57.

7. Getabelew A, Aman M, Fantaye E, Yeheyis T. Prevalence of neonatal sepsis and associated factors among neonates in neonatal intensive care unit at selected governmental hospitals in Shashemene Town, Oromia Regional State, Ethiopia, 2017. Int J Pediatrics. 2018;2018.

8. Woldu MA, Guta MB, Lenjisa JL, Tegegne GT, Tesafye G, Dinsa H. Assessment of the incidence of neonatal sepsis, its risk factors, antimicrobials use and clinical outcomes in Bishoftu General Hospital, neonatal intensive care unit, DebrezeitEthiopia. Int J Contemp Pediatrics. 2017;1(3):135-41.

9. Debelew GT, Afework MF, Yalew AW. Determinants and causes of neonatal mortality in Jimma zone, Southwest Ethiopia: a multilevel analysis of prospective follow up study. PLoS One. 2014;9(9):e107184.

10. Roba AA and Diro DH. Morbidities, Rate and Time Trends of Neonatal Mortality in Dilchora Referral Hospital, Dire Dawa, Ethiopia, 2012-2017. Austin Med Sci. 2017;2(2):1019.

11. Tewabe T, Mohammed S, Tilahun Y, Melaku B, Fenta M, Dagnaw T, Belachew A, Molla A, Belete $\mathrm{H}$. Clinical outcome and risk factors of neonatal sepsis among neonates in Felege Hiwot referral hospital, Bahir Dar, Amhara regional state, north West Ethiopia 2016: a retrospective chart review. BMC Res Notes. 2017;10(1):265.

12. Tewabe T, Mehariw Y, Negatie E, Yibeltal B. Neonatal mortality in the case of Felege Hiwot referral hospital, Bahir Dar, Amhara regional state, north West Ethiopia 2016: a one year retrospective chart review. Ital J Pediatr. 2018;44(1):57.

13. Sime $\mathrm{H}$, Workneh $\mathrm{N}$. Morbidity and mortality of neonates admitted in Jimma University specialized hospital Paediatrics neonatal Ward: a one year retrospective analysis. Ethiop J Pediatrics Child Health. 2014;10(10):44-54

14. Liberati A, Altman DG, Tetzlaff J, Mulrow C, Gotzsche PC, loannidis JP, et al. The PRISMA statement for reporting systematic reviews and meta-analyses of studies that evaluate healthcare interventions: explanation and elaboration. 2009;339:b2700. https://doi.org/10.1136/bmj.b2700.

15. Newcastle-Ottawa Scale customized for cross-sectional studies. In. available from https://static-content.springer.com/esm/../12889_2012_5111_MOESM3_ESM.doc.

16. Malta M, Cardoso LO, Bastos FI, Magnanini MM, Silva CM. STROBE initiative: guidelines on reporting observational studies. Saude Publica. 2010;44(3): 559-65. https://doi.org/10.1590/S0034-89102010000300021Rev.

17. Rücker G, Schwarzer G, Carpenter JR, Schumacher M. Undue reliance on I 2 in assessing heterogeneity may mislead. BMC Med Res Methodol. 2008;8:79. https://doi.org/10.1186/1471-2288-8-79.

18. Borenstein M, Hedges LV, Higgins J, Rothstein HR. A basic introduction to fixed-effect and random-effects models for meta-analysis. Res Synth Methods. 2010;1(2):97-111. https://doi.org/10.1002/jrsm.12.

19. Ghiorghis B. Neonatal sepsis in Addis Ababa, Ethiopia: a review of 151 bacteremic neonates. Ethiop Med J. 1997;35(3):169-76.

20. Gebremedhin D, Berhe $H$, Gebrekirstos K. Risk factors for neonatal sepsis in public hospitals of Mekelle City, North Ethiopia, 2015: unmatched case control study. PLoS One. 2016;11(5):e0154798.

21. Shitaye D, Asrat D, Woldeamanuel Y, Worku B. Risk factors and etiology of neonatal sepsis in Tikur Anbessa University hospital, Ethiopia. Ethiop Med J. 2010;48(1):11-21.
22. Moges F, Eshetie S, Yeshitela B, Abate E. Bacterial etiologic agents causing neonatal sepsis and associated risk factors in Gondar, Northwest Ethiopia. BMC Pediatrics. 2017;17(1):137.

23. Gerensea $\mathrm{H}$. Trend and pattern of neonatal morbidity and mortality in Tigray region, Ethiopia Edorium. J Pediatrics. 2017;1:1-5.

24. Fleischmann-Struzek C, Goldfarb DM, Schlattmann P, Schlapbach LJ, Reinhart K, Kissoon N. The global burden of paediatric and neonatal sepsis: a systematic review. Lancet Respir Med. 2018;6(3):223-30.

25. Le Geyt J, Hauck S. G272 epidemiological trends of neonatal sepsis in a county referral hospital in Central Kenya; 2016.

26. Medugu N, Iregbu K, Tam PY, Obaro S. Aetiology of neonatal sepsis in Nigeria, and relevance of group b streptococcus: a systematic review. PLoS One. 2018;13(7):e0200350.

27. Verma P, Berwal PK, Nagaraj N, Swami S, Jivaji P, Narayan S. Neonatal sepsis: epidemiology, clinical spectrum, recent antimicrobial agents and their antibiotic susceptibility pattern. Int J Contemp Pediatrics. 2017;2(3):176-80.

28. Jabiri A, Wella HL, Semiono A, Saria A, Protas J. Prevalence and factors associated with neonatal sepsis among neonates in Temeke and Mwananyamala Hospitals in Dar es Salaam, Tanzania. Tanzania J Health Res. 2016;18(4).

29. El-Din S, Rabie EM, El-Sokkary MM, Bassiouny MR, Hassan R. Epidemiology of neonatal sepsis and implicated pathogens: a study from Egypt. Biomed Res Int. 2015;2015.

30. Chan GJ, Lee AC, Baqui AH, Tan J, Black RE. Prevalence of early-onset neonatal infection among newborns of mothers with bacterial infection or colonization: a systematic review and meta-analysis. BMC Infect Dis. 2015; 15(1):118

31. Simonsen KA, Anderson-Berry AL, Delair SF, Davies HD. Early-onset neonatal sepsis. Clin Microbiol Rev. 2014;27(1):21-47.

32. Al Kibria GM, Burrowes V, Choudhury A, Sharmeen A, Ghosh S, Mahmud A Angela KC. Determinants of early neonatal mortality in Afghanistan: an analysis of the demographic and health survey 2015. Glob Health. 2018;14(1):47.

33. Dong Y, Speer CP. Late-onset neonatal sepsis: recent developments. Archives of Disease in Childhood-Fetal and Neonatal Edition. 2015;100(3): F257-63.

34. Åberg K. Neonatal complications following birth by vacuum extraction. Inst för kvinnors och barns hälsa/Dept of Women's and Children's Health; 2017. 978-91-7676-839-6.

35. Leante-Castellanos JL, Lloreda-García JM, García-González A, Llopis-Baño C, Fuentes-Gutiérrez C, Alonso-Gallego JÁ, Martínez-Gimeno A. Centralperipheral temperature gradient: an early diagnostic sign of late-onset neonatal sepsis in very low birth weight infants. 2012;40(5):571-6.

\section{Publisher's Note}

Springer Nature remains neutral with regard to jurisdictional claims in published maps and institutional affiliations.

Ready to submit your research? Choose BMC and benefit from:

- fast, convenient online submission

- thorough peer review by experienced researchers in your field

- rapid publication on acceptance

- support for research data, including large and complex data types

- gold Open Access which fosters wider collaboration and increased citations

- maximum visibility for your research: over $100 \mathrm{M}$ website views per year

At BMC, research is always in progress.

Learn more biomedcentral.com/submissions 